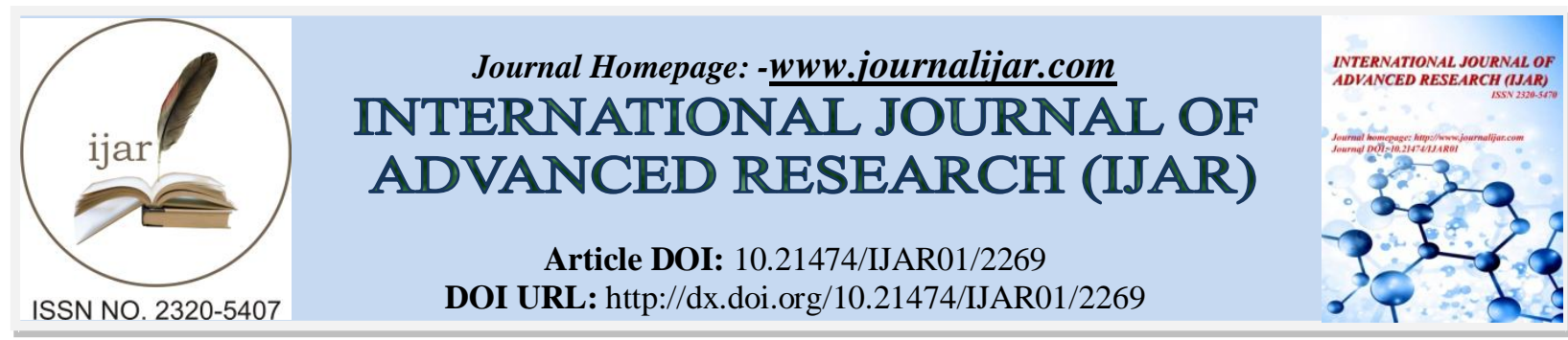

RESEARCH ARTICLE

\title{
TIP TO HUB VERTICAL RECAPPING AN ALTERNATIVE METHOD TO ONE HAND RECAPPING TECHNIQUE.
}

Palanisamy Jayakumar ${ }^{1}$, Dhevendran Maruthupandian ${ }^{1}$ and Subramaniam Senthilkumar ${ }^{2}$.

1. Department of General Surgery, Madurai Medical College and Government Rajaji Hospital, Madurai, India.

2. Department of Public Health and Preventive Medicine, Madurai, India.

\section{Manuscript Info}

Manuscript History

Received: 29 September 2016

Final Accepted: 30 October 2016

Published: November 2016

Key words:-

Needle Recapping, Tip To Hub,

Vertical Recapping

\section{Abstract}

Occupational exposure in healthcare setting is a major issue in the spread of Human Immunodeficiency Virus, Hepatitis B virus and Hepatitis C virus for healthcare workers. Following Universal Precaution and not recapping the needle are the two important factors reducing the occupational exposures. Universal precaution practices are not followed properly by healthcare professionals. When needle recapping is needed by chance use "One Hand recapping" or "Tip to Hub Vertical Recapping" and " Standard Operative Procedure" to reduce the needle stick injuries.

Copy Right, IJAR, 2016,. All rights reserved.

\section{Introduction:-}

After the emergence of Acquired Immune Deficiency Syndrome (AIDS)Virus in Africa, heathcare workers' attention has risen to protect themselves from blood borne infections. Blood Borne Pathogens(BBPs) include Human Immunodeficiency Virus(HIV), Hepatitis B and Hepatitis C viruses. Because of Universal precaution practices, Using sharp containers, Needle destroyer and Not Recapping the needle, occupational needle stick injuries(NSI) are in decreasing trend[1]. But studies show inconsistant result and low quality evidence for safety devices in reducing needle stick injuries[2]. Sharp injuries for healthcare professionals are due to Low Compliance with Universal Precaution, Needle recapping, Giving injections in ward area or Patients Room, Emergency Rooms, Inadequate staff, insufficient training, Low availability of protective strategies, duty overload and fatigue[3-8]. Needle recapping is a major concern in NSI's[6-10].

\section{How to Recap?}

Even though recapping of needle is not a recommended procedure, recapping can be done till the safe disposal of the used needles, to avoid injuries to self and other healthcare workers. When recapping is needed it should be done with mechanical device or "One Hand" recapping technique[11,12].

Here we proposed a Tip to Hub Vertical Recapping technique, when One Hand technique is not feasible like where a flat stable surface is not available.

Standard Operative Procedure(SOP) is useful in healthcare by reducing the errors in the procedure and for better results[13-16].

In both the techniques follow standard operative procedure by following the steps given below.

Corresponding Author:-Palanisamy Jayakumar.

Address:- Department of General Surgery, Madurai Medical College and Government Rajaji Hospital, 


\section{Recapping Techniques:-}

The "One-Hand" Technique:-

Step 1: Place the cap on a flat surface, then remove your hand from the cap(Figure1 \& 2).

Step 2 : With one hand, hold the syringe and use the needle to "scoop up" the cap(Figure 3).

Step 3: When the cap covers the needle completely, use the other hand to secure the cap on the needle hub. Be careful to handle the cap at the bottom only (near the hub)(Figure 4).

\section{Tip to hub vertical recapping:-}

Step 1:- Hold the used syringe in upright position (Needle tip upwards)(Figure 5).

Step 2:- Hold the tip of the cap and bring the hub of the cap near to tip of the needle(Figure 6).

Step 3:- Enter the tip of the needle just into the cap, move the needle or cap side to side to ensure the needle is inside the cap (Figure 7).

Step 4:- Let the cap down by releasing your fingers from the cap, after releasing the cap, fingers and hand must swing away from the cap and come down to hub of the cap (Figure 8).

Step 5:- Lock the cap with needle by holding the base of the cap(Figure 9).

Step 3 in One hand technique and Step 5 in Tip to hub vertical recapping are the same.

\section{When to Recap?}

When and where safety devices are not available like remote camps, house visits, small clinics, Ambulances etc. 

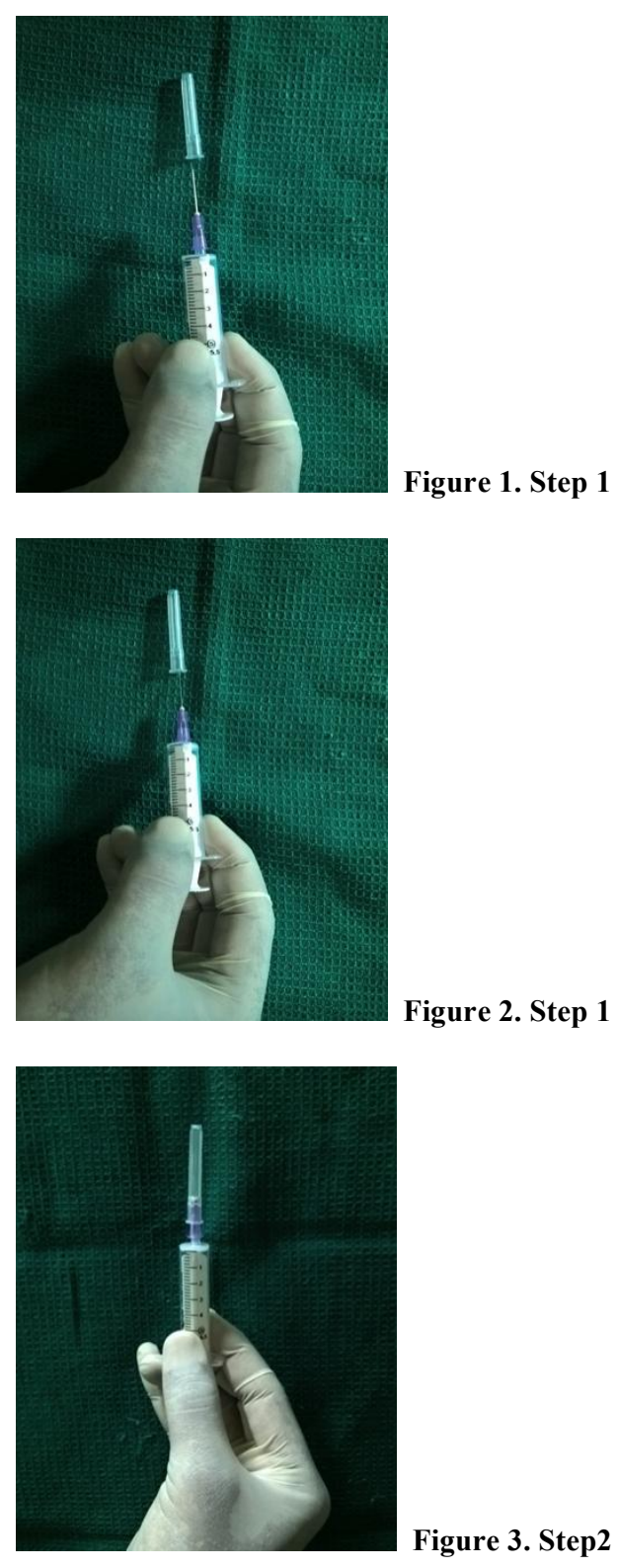

Figure 3. Step2

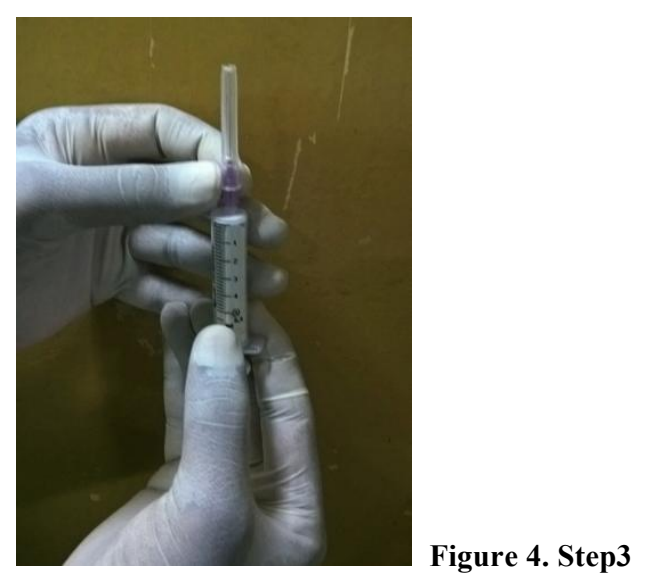




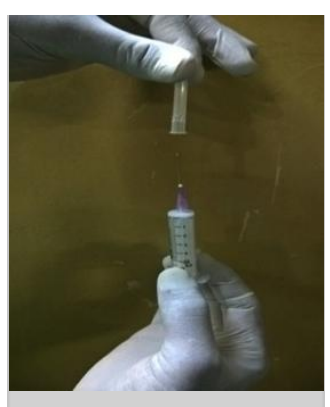

Figure 5. Step 1

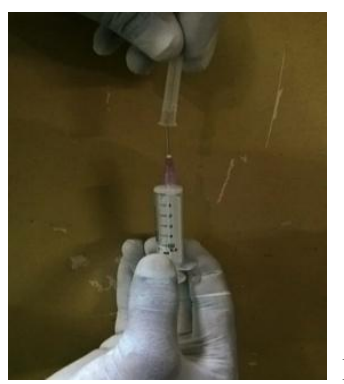

Figure 6. Step 2

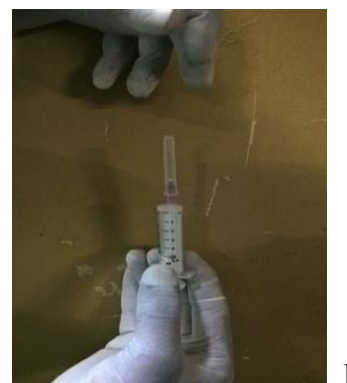

Figure 7. Step 3

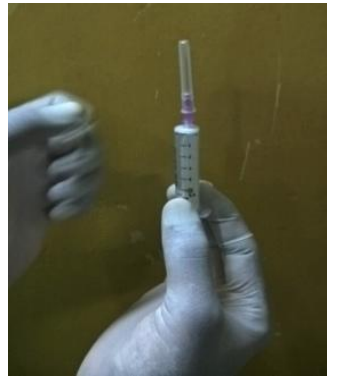

Figure 8. Step 4

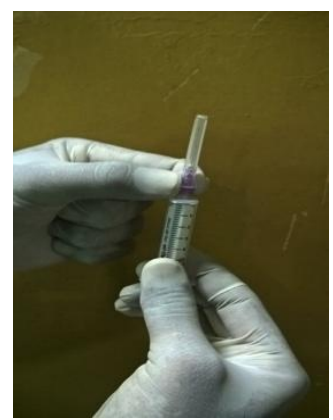

Figure 9. Step 5 


\section{Discussion:-}

Emergence of BBPs mandates health workers to adopt universal precaution and avoid needle recapping, but inconsistent results in following universal precaution and needle recapping happens around the globe. Needle recapping is not a recommended procedure, but is happening around the world everyday which pushed us to urge for safe recapping techniques and following SOP.

\section{Conclusion:-}

Occupational needle stick injuries should be prevented in healthcare setting by education, training and regular updating of knowledge and protective materials. "One Hand" and "Tip to Hub Vertical" Recapping technique should be used when other standard disposal practices are not possible.SOP should be followed in needle recapping and its disposal. Efficacy of these techniques should be evaluated by further studies.

\section{References:-}

1. Wilburn SQ.Needlestick and sharps injury prevention.Online J Issues Nurs. 2004 Sep 30;9(3):5.

2. Lavoie MC, Verbeek JH, PahwaM.Devices for preventing percutaneous exposure injuries caused by needles in healthcare personnel. Cochrane Database Syst Rev. 2014 Mar 9;3:CD009740. doi: 10.1002/14651858.CD009740.pub2.

3. Watterson L.Monitoring sharps injuries: EPINet surveillance results.Nurs Stand. 2004 Sep 29-Oct 5;19(3):33-8.

4. Dorevitch S, ForstL.The occupational hazards of emergency physicians.Am J Emerg Med. 2000 May;18(3):300-11.

5. Watson K, Williams-Johnson J, Watson H, Walters C, Williams EW, Eldemire-Shearer D.The Compliance of Healthcare Workers with Universal Precautions in the Emergency Room at the University Hospital of the West Indies.West Indian Med J. 2014 Jun 11;63(3):220-229. doi: 10.7727/wimj.2014.044.

6. Malik A, Shaukat MS, QureshiA.Needle-stick injury: a rising bio-hazard.JAyub Med CollAbbottabad. 2012 JulDec;24(3-4):144-6.

7. Liyanage IK, Caldera T, Rwma R, Liyange CK, De Silva P, KarunathilakeIM.Sharps injuries among medical students in the Faculty of Medicine, Colombo, Sri Lanka.Int J Occup Med Environ Health. 2012 Jun;25(3):27580. doi: 10.2478/S13382-012-0036-4.

8. Askarian M, Malekmakan L, Memish ZA, AssadianO.Prevalence of needle stick injuries among dental, nursing and midwifery students in Shiraz, Iran.GMSKrankenhhygInterdiszip. 2012;7(1):Doc05. doi: 10.3205/dgkh000189.

9. Rehan HS, Chopra D, Sah RK, Chawla T, Agarwal A, Sharma GK.Injection practices of healthcare professionals in a Tertiary Care Hospital.J Infect Public Health. 2012 Apr;5(2):177-81. doi: 10.1016/j.jiph.2012.01.001.

10. Enwere OO, DiweKC.Knowledge, perception and practice of injection safety and healthcare waste management among teaching hospital staff in south east Nigeria: an intervention study.PanAfr Med J. 2014 Mar 19;17:218. doi: 10.11604/pamj.2014.17.218.3084. eCollection 2014.

11. http://www.fda.gov/MedicalDevices/ProductsandMedicalProcedures/HomeHealthandConsumer/ConsumerProd ucts/Sharps/ucm263259.htm [Accesed on 11-01-2015]

12. https://www.uthsc.edu/safety/pdfs/needle_safety.pdf [Accessed on 11-01-2015]

13. Rognås L, Hansen TM, Kirkegaard H, TønnesenE.Standard operating procedure changed pre-hospital critical care anaesthesiologists' behaviour: a quality control study.Scand J Trauma ResuscEmerg Med. 2013 Dec 5;21:84. doi: 10.1186/1757-7241-21-84.

14. Bernini P, Bertini I, Luchinat C, Nincheri P, Staderini S, TuranoP.Standard operating procedures for preanalytical handling of blood and urine for metabolomic studies and biobanks.JBiomol NMR. 2011 Apr;49(34):231-43. doi: 10.1007/s10858-011-9489-1.

15. Tuck MK, Chan DW, Chia D, Godwin AK, Grizzle WE, Krueger KE, Rom W, Sanda M, Sorbara L, Stass S, Wang W, Brenner DE.Standard operating procedures for serum and plasma collection: early detection research network consensus statement standard operating procedure integration working group.J Proteome Res. 2009 Jan;8(1):113-7. doi: 10.1021/pr800545q.

16. Lewczuk P, Kornhuber J, WiltfangJ.The German Competence Net Dementias: standard operating procedures for the neurochemical dementia diagnostics.J Neural Transm. 2006 Aug;113(8):1075-80. 